\title{
Original
}

\section{Effectiveness of three methods for evaluating root canal anatomy of mandibular incisors}

\author{
Marina C. Prado1), Heloisa Gusman²), Felipe G. Belladonna3), \\ Maíra Prado2), and Fabíola Ormiga 2 ) \\ 1)Proclin Department, School of Dentistry, Rio de Janeiro State University, Rio de Janeiro, RJ, Brazil \\ 2)Department of Dental Clinic, School of Dentistry, Federal University of Rio de Janeiro, Rio de Janeiro, RJ, \\ Brazil \\ 3)Department of Endodontics, Fluminense Federal University, Niterói, RJ, Brazil
}

(Received December 22, 2015; Accepted February 26, 2016)

\begin{abstract}
This study compared the effectiveness of clinical observation, clinical microscopic observation, and tooth-clearing technique in determining the number of canals in mandibular incisors. Root canal ramifications were also analyzed. Using clinical and microscopic analyses, we determined the number of canal entrances in $\mathbf{2 7 7}$ mandibular incisors. In addition, tooth-clearing technique was used to determine the number of canals and frequency of ramifications in the samples. The kappa coefficient was used to compare the different methods with regard to frequency of canals. Most teeth had one canal entrance. The proportion of teeth with two canals was $23.5 \%$ by tooth-clearing analysis, $5.8 \%$ by clinical microscopy, and $1.1 \%$ by clinical analysis. A large number of samples had some type of ramification $(40.1 \%)$, and most ramifications were present in teeth with two canals. The most frequent ramification was lateral canals $(8.3 \%)$. Clinical microscopy improved identification of a second canal in mandibular incisors. However, it did not identify second canals in all teeth with two canals. (J Oral Sci 58, 347-351, 2016)
\end{abstract}

Keywords: dental pulp cavity; endodontics; incidence; microscopy; root canal therapy.

Correspondence to Dr. Marina Carvalho Prado, Estrada do Campinho 298A, Campo Grande, Rio de Janeiro, RJ 23070-220, Brazil

Fax:+55-21-24131442 E-mail: marinaprado@dentistas.com.br

doi.org/10.2334/josnusd.15-0730

DN/JST.JSTAGE/josnusd/15-0730

\section{Introduction}

Successful endodontic treatment depends on the clinician's ability to shape, clean, and fill the root canal system (RCS). Removal of vital and necrotic tissues, microorganisms, and their products from the RCS is one of the most important aspects of treatment $(1,2)$. Knowledge of the RCS anatomy is required because routine preoperative radiography yields a two-dimensional image of this complex three-dimensional system and information provided by clinical observation is usually limited to the characteristics of the pulp chamber and canal entrances $(3,4)$.

Despite their simple external anatomy, mandibular incisors have a complex internal morphology, and studies have reported varying anatomic features for this group of teeth (5-14). Madeira and Hetem (5) used a tooth-clearing technique to study the root canal morphology of 1,179 mandibular incisors and reported that $11.5 \%$ of the teeth had two canals. Using the same technique, Vertucci (7) examined 300 mandibular anterior teeth and observed two canals in $27.5 \%$ of teeth. Kartal and Yanikoglu (8) also used tooth-clearing technique to analyze 100 mandibular incisors and observed two canals in $41.4 \%$ of teeth. Using a modeling technique, Gomes et al. (10) confirmed the presence of two canals in $36 \%$ of 111 mandibular incisors. In a recent study using micro-computed tomography (micro-CT) analysis, Leoni et al. (12) identified two canals at $1 \mathrm{~mm}$ from the apical foramen in $20 \%$ of 200 mandibular incisors. Fernandes et al. (13) also used micro-CT imaging and observed two canals in $40 \%$ of 
40 mandibular incisors. In a recent study, Silva et al. (14) examined 1,200 maxillary and mandibular anterior teeth from patients who required cone-beam computed tomography (CBCT). They observed that, although a single canal was detected in $98 \%$ of teeth, the proportions of mandibular central and lateral incisors with two canals were high (35.5\% and $39.5 \%$, respectively).

Advances in several new techniques have improved the outcomes and predictability of endodontic treatment, as these techniques assist clinicians in obtaining additional information on root canal morphology (15). In dentistry, clinical microscopy has improved endodontic practice because it provides a better visual field and makes procedures easier and safer $(16,17)$. In addition, clinical microscopy can reveal canal entrances that are difficult to identify during conventional clinical procedures (18). This study compared the effectiveness of clinical observation, clinical microscopic observation, and tooth-clearing technique in determining the number of canals in mandibular incisors. Root canal ramifications were also analyzed.

\section{Materials and Methods}

The study specimens were 277 extracted human permanent mandibular incisors, which were investigated after obtaining the approval of the Ethics Committee of Federal University of Rio de Janeiro (CAAE 1405.0.000.239-08). The samples were stored in a $10 \%$ formaldehyde solution until required and washed in running water for $24 \mathrm{~h}$ to eliminate any remaining solution. Teeth with incomplete root formation, evidence of previous endodontic treatment, calcifications, or resorptions were excluded. The coronal length, root length, and total length of the teeth were measured on the mesial surface, using an electronic digital caliper with an accuracy of $0.001 \mathrm{~mm}$ (United Precision Machine, Shenzhen, China).

An endodontic access cavity was prepared in all teeth with compensatory wear at the lingual surface. Samples were immersed in $5.25 \%$ sodium hypochlorite for $12 \mathrm{~h}$ to facilitate pulp tissue dissolution. The specimens were then submerged in an ultrasonic bath, rinsed in running tap water for $4 \mathrm{~h}$, and dried. Two independent evaluators assessed the number of canal entrances through the pulp chamber, by means of clinical observation and clinical microscopy at $16 \times$ magnification (DF Vasconcelos, São Paulo, Brazil). A size $10 \mathrm{~K}$-file (Dentsply, Ballaigues, Switzerland) was used to explore the canals identified and achieve patency.

After clinical and microscopic analysis, tooth-clearing technique was used to observe the internal anatomy of the teeth, according to the method of Barbosa et al. (19)
Table 1 Number of canals observed, according to method of analysis

\begin{tabular}{lcc}
\hline & \multicolumn{2}{c}{ Number of canals $(\%)$} \\
\cline { 2 - 3 } & 1 & 2 \\
\hline Clinical analysis & 98.9 & 1.1 \\
Microscopic analysis & 94.2 & 5.8 \\
Tooth-clearing analysis & 76.5 & 23.5 \\
\hline
\end{tabular}

with modifications. In brief, the teeth were decalcified by immersing them in a 5\% hydrochloric acid solution for approximately 3 days at room temperature. The decalcifying solution was changed every $24 \mathrm{~h}$ and agitated for $10 \mathrm{~s}$ twice daily. Upon completion of the decalcifying process, the teeth were rinsed in running water for $12 \mathrm{~h}$ to eliminate any trace of the acidic substance. The teeth were then dehydrated in different grades of ethyl alcohol $(75 \%, 85 \%, 96 \%$, and $100 \%)$ by immersing them in each solution for $4 \mathrm{~h}$. To reveal the RCS, a colorless gelatin was mixed with Indian ink, inserted in empty anesthetic tubes, and injected into the RCS with the aid of a needle and a carpule syringe. The teeth were then immersed in $100 \%$ alcohol for $4 \mathrm{~h}$ and dried. Last, the specimens were placed in methyl salicylate, which rendered them transparent after $3 \mathrm{~h}$. The transparent specimens were examined by three previously calibrated and independent endodontists, who analyzed the number of canals and their ramifications.

\section{Statistical analysis}

The kappa coefficient ( $\kappa$ ) was used to evaluate reliability among evaluators and to compare the different methods with regard to the number of canals identified. The chisquare test $\left(\chi^{2}, P<0.05\right)$ was used to assess correlations between the number of canals and frequency of ramifications.

\section{Results}

Reliability among evaluators was considered perfect $(\kappa=$ 1.000 for all variables measured). The coronal, root, and total lengths of the teeth were $6.8( \pm 0.21), 14.9( \pm 0.48)$, and $21.6( \pm 0.69) \mathrm{mm}$, respectively. Table 1 summarizes the number of canals, as determined by each method. Most teeth had a single canal entrance, irrespective of method of analysis. However, the number of canals detected varied in relation to the method of analysis. Tooth-clearing analysis revealed a larger proportion of teeth with two canals $(23.5 \%)$ than either clinical microscopic analysis $(5.8 \% ; \kappa=0.333)$ or clinical analysis $(1.1 \% ; \kappa=0.303)$. 


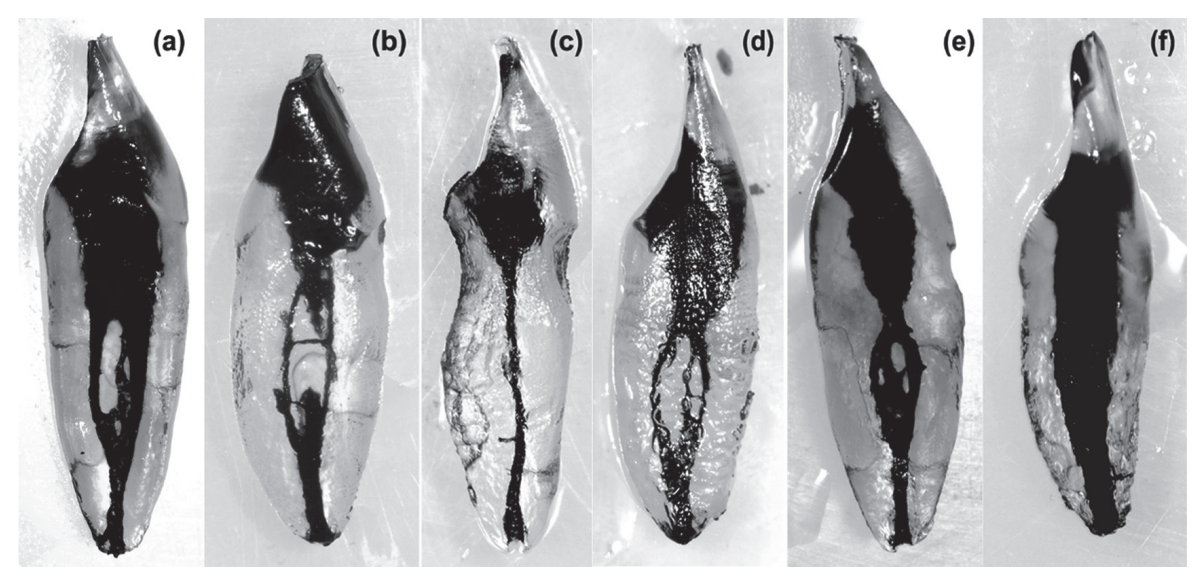

Fig. 1 Ramification types observed after tooth-clearing technique: (a) apical delta canals; (b) intercanal; (c) lateral; (d) recurrent; (e) reticular; (f) secondary.

Table 2 Frequency of ramification type, according to number of canals

\begin{tabular}{lccc}
\hline Ramification type & $\begin{array}{c}\text { Teeth with one canal } \\
(n=212)\end{array}$ & $\begin{array}{c}\text { Teeth with two canals } \\
(n=65)\end{array}$ & $\begin{array}{c}\text { Total } \\
(n=277)\end{array}$ \\
\hline Accessory & $0(0 \%)$ & $0(0 \%)$ & $0(0 \%)$ \\
Collateral & $0(0 \%)$ & $2(3.1 \%)$ & $2(0.7 \%)$ \\
Apical delta & $8(3.8 \%)$ & $3(4.6 \%)$ & $11(4.0 \%)$ \\
Intercanal & $0(0 \%)$ & $19(29.2 \%)$ & $19(6.9 \%)$ \\
Lateral & $17(8.0 \%)$ & $6(9.2 \%)$ & $23(8.3 \%)$ \\
Recurrent & $1(0.5 \%)$ & $9(13.9 \%)$ & $10(3.6 \%)$ \\
Reticular & $0(0 \%)$ & $19(29.3 \%)$ & $19(6.9 \%)$ \\
Secondary & $7(3.3 \%)$ & $0(0 \%)$ & $7(2.5 \%)$ \\
Total & $33(15.6 \%)$ & $58(89.2 \%)$ & $91(40.1 \%)$ \\
\hline
\end{tabular}

Tooth-clearing analysis revealed various ramifications, including lateral, intercanal, recurrent, reticular, and secondary canals, as well as apical deltas (Fig. 1). Table 2 shows the frequency of the various ramifications in relation to the number of canals; $40.1 \%$ of teeth had some type of ramification, and teeth with two canals had a significantly higher number of ramifications than teeth with one canal $\left(P<0.05 ; \chi^{2}\right.$ test $)$. The most frequently observed ramifications were lateral canals $(8.3 \%)$, reticular canals $(6.9 \%)$, and intercanals $(6.9 \%)$.

\section{Discussion}

This study compared the results of clinical observation, clinical microscopic observation, and tooth-clearing technique in characterizing the RCS anatomy of mandibular incisors. The findings indicate that the number of canals observed was influenced by the analytical method: tooth-clearing analysis was the most effective method for identifying teeth with two canals, followed by microscopic analysis and then clinical analysis.

Several methods are used to investigate root canal morphology, including root sectioning, modeling, radiographic examination, tooth-clearing technique, and CBCT and micro-CT imaging (3,5,20-24). Micro-CT and tooth-clearing technique are considered the gold standards for such assessment $(13,23)$. A recent study (23) compared the efficacy of four tomography methods with digital radiography and a modified tooth-clearing technique and concluded that only two tomography methods, CBCT and peripheral quantitative computed tomography (pQCT), were as accurate as canal staining and tooth-clearing technique in identifying root canal systems.

We did not attempt to subdivide the present sample into central and lateral incisors, as some previous studies found no significant difference in anatomy between these groups $(5,12,20)$. The present results showed an average total tooth length of $21.6( \pm 0.69) \mathrm{mm}$, which accords with the findings of a previous study (6). Most teeth observed in this study were found to have a single canal entrance, irrespective of the method of analysis. These results are in agreement with those of previous studies $(5,7,8,10,12,14)$, which reported the presence of a single canal in most teeth, as determined by tooth-clearing 
technique, modeling, and micro-CT and $\mathrm{CBCT}$ imaging.

In the present analysis, the number of teeth with two canals was higher for clinical microscopic analysis than for clinical analysis, perhaps because the bifurcation of the main canal in the middle third of most teeth with two canals was difficult to observe clinically. Thus, use of dental microscopy was required in order to provide the magnification and intense illumination needed to observe the second canal $(16,25)$. However, even dental microscopy was not efficient in identifying all teeth with two canals, as the number of such teeth identified was substantially higher for tooth-clearing technique. Studies of the root canal morphology of mandibular incisors found that the frequency of teeth with two canals never exceeded that of teeth with one main canal $(3,5,7,8,11,26)$. Using tooth-clearing technique, we identified two canals in $23.5 \%$ of teeth. Our results agree with those of previous studies $(6,7,11,12)$, which identified two canals in $20-27.5 \%$ of the total sample. However, our results differ from those reported in some other studies $(3,5,8,10,13)$, which identified two main canals in $11.5 \%, 41.4 \%, 36.0 \%, 3.0 \%$, and $40.0 \%$ of the sample. This discrepancy is probably related to differences in methodology, terminology, and study population.

Tooth-clearing analysis revealed various ramifications, including lateral, intercanal, recurrent, reticular, and secondary canals, as well as apical deltas. The most frequent ramification was lateral canals $(8.3 \%)$, as was the case in a number of previous studies (6-11). The number of ramifications was significantly higher for teeth with two canals than for teeth with one canal, as was noted in a previous study (22). These results suggest that RCS complexity is positively associated with the number of canals. In the present sample, $40.1 \%$ of teeth had some type of ramification, which is capable of hosting microorganisms and sustaining infection in the RCS $(27,28)$. Because most ramifications are mechanically inaccessible, root canals must be abundantly irrigated with a solution that has antimicrobial properties and the ability to dissolve tissue remnants, such as sodium hypochlorite (29).

In conclusion, the number of canals identified was related to the analytical method used: tooth-clearing analysis was the most effective method for identifying teeth with two canals, followed by microscopic analysis and then clinical analysis. Clinical microscopy improved identification of the second canal in mandibular incisors but did not identify the second canal in all teeth with two canals.

\section{References}

1. Sjögren U, Hagglund B, Sundqvist G, Wing K (1990) Factors affecting the long-term results of endodontic treatment. J Endod 16, 498-504.

2. Endal U, Shen Y, Knut A, Gao Y, Haapasalo M (2011) A high-resolution computed tomographic study of changes in root canal isthmus area by instrumentation and root filling. $\mathrm{J}$ Endod 37, 223-227.

3. Mauger MJ, Schindler WG, Walker WA (1998) An evaluation of canal morphology at different levels of root resection in mandibular incisors. J Endod 24, 607-609.

4. Scarfe WC, Levin MD, Gane D, Farman AG (2009) Use of cone beam computed tomography in endodontics. Int J Dent 2009: 634567.

5. Madeira MC, Hetem S (1973) Incidence of bifurcations in mandibular incisors. Oral Surg Oral Med Oral Pathol 36, 589-591.

6. De Deus QD (1975) Frequency, location, and direction of the lateral, secondary, and accessory canals. J Endod 1, 361-366.

7. Vertucci FJ (1984) Root canal anatomy of the human permanent teeth. Oral Surg Oral Med Oral Pathol 58, 589-599.

8. Kartal N, Yanikoğlu FÇ (1992) Root canal morphology of mandibular incisors. J Endod 18, 562-564.

9. Karagöz-Küçükay I (1994) Root canal ramifications in mandibular incisors and efficacy of low-temperature injection thermoplasticized gutta-percha filling. J Endod 20, 236-240.

10. Gomes BPFA, Rodrigues HH, Tancredo N (1996) The use of a modelling technique to investigate the root canal morphology of mandibular incisors. Int Endod J 29, 29-36.

11. Al-Qudah AA, Awawdeh LA (2006) Root canal morphology of mandibular incisors in a Jordanian population. Int Endod J 39, 873-877.

12. Leoni GB, Versiani MA, Pécora JD, Sousa-Neto MD (2014) Micro-computed tomographic analysis of the root canal morphology of mandibular incisors. J Endod 40, 710-716.

13. Fernandes LMPS, Rice D, Ordinola-Zapata R, Alvares Capelozza AL, Bramante CM, Jaramillo D et al. (2014) Detection of various anatomic patterns of root canals in mandibular incisors using digital periapical radiography, 3 cone-beam computed tomographic scanners, and microcomputed tomographic imaging. J Endod 40, 42-45.

14. Silva EJ, Castro RW, Nejaim Y, Silva AI, Haiter-Neto F, Silberman A et al. (2016) Evaluation of root canal configuration of maxillary and mandibular anterior teeth using cone beam computed tomography: an in-vivo study. Quintessence Int 47, 19-24.

15. Plotino G, Pameijer CH, Grande NM, Somma F (2007) Ultrasonics in endodontics: a review of the literature. J Endod 33, 81-95.

16. de Carvalho MC, Zuolo ML (2000) Orifice locating with a microscope. J Endod 26, 532-534.

17. West JD (2000) The role of the microscope in 21st century endodontics: visions of a new frontier. Dent Today 19, 62-64, 66-69.

18. Carr GB, Murgel CAF (2010) The use of operating micro- 
scope in endodontics. Dent Clin North Am 54, 191-214.

19. Barbosa FO, Gusman H, Araújo MCP (2009) A comparative study on the frequency, location, and direction of accessory canals filled with the hydraulic vertical condensation and continuous wave of condensation techniques. J Endod 35, 397-400.

20. Kaffe I, Kaufman A, Littner MM, Lazarson A (1985) Radiographic study of the root canal system of mandibular anterior teeth. Int Endod J 18, 253-259.

21. Walker RT (1988) The root canal anatomy of mandibular incisors in a southern Chinese population. Int Endod J 21, 218-223.

22. Miyashita M, Kasahara E, Yasuda E, Yamamoto A, Sekizawa $\mathrm{T}$ (1997) Root canal system of the mandibular incisor. J Endod 23, 479-484.

23. Neelakantan P, Subbarao C, Subbarao CV (2010) Comparative evaluation of modified canal staining and clearing technique, cone-beam computed tomography, peripheral quantitative computed tomography, spiral computed tomography and plain and contrast medium-enhanced digital radiography in studying root canal morphology. J Endod 36, 1547-1551.

24. Almeida MM, Bernardineli N, Ordinola-Zapata R, VillasBôas MH, Amoroso-Silva PA, Brandão CG et al. (2013) Micro-computed tomography analysis of the root canal anatomy and prevalence of oval canals in mandibular incisors. J Endod 39, 1529-1533.

25. Görduysus MO, Görduysus M, Friedman S (2001) Operating microscope improves negotiation of second mesiobuccal canals in maxillary molars. J Endod 27, 683-686.

26. Sert S, Aslanalp V, Tanalp J (2004) Investigation of the root canal configurations of mandibular permanent teeth in the Turkish population. Int Endod J 37, 494-499.

27. Silveira CF, Martos J, Neto JB, Ferrer-Luque CM, Silveira LF (2010) Clinical importance of the presence of lateral canals in endodontics. Gen Dent 58, e80-83.

28. Riccuci D, Loghin S, Siqueira JF Jr (2013) Exuberant biofilm infection in a lateral canal as the cause of short-term endodontic treatment failure: report of a case. J Endod 39, 712-718.

29. Zehnder M (2006) Root canal irrigants. J Endod 32, 389-398. 